\title{
Research Paper: The Role of Social Cognition in Predicting the Social Functioning in Patients With Chronic Schizophrenia
}

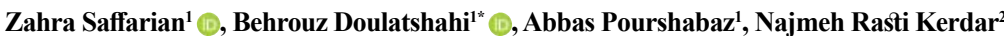 \\ 1. Department of Clinical Psychology, University of Social Welfare and Rehabilitation Sciences, Tehran, Iran. \\ 2. Institute for Cognitive \& Brain Sciences, Shahid Beheshti University, Tehran, Iran.
}

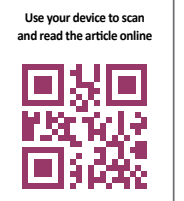

Citation Saffarian Z, Doulatshahi B, Pourshabaz A, Rasti Kerdar N. The Role of Social Cognition in Predicting the Social Functioning in Patients With Chronic Schizophrenia. Iranian Rehabilitation Journal. 2018; 16(3):239-246. http:// dx.doi.org/10.32598/irj.16.3.239

http://dx.doi.org/10.32598/irj.16.3.239

\section{(c) (1) (8)}

Funding: See Page 244

Article info:

Received: 27 Feb 2018

Accepted: 05 Jul 2018

Available Online: 01 Sep 2018

\section{Keywords:}

Social cognition, Theory of mind, Emotion perception, Attributional style, Social function

\section{ABSTRACT}

Objectives: Patients with schizophrenia are characterized with deficiencies in various aspects of social functioning. Given the relationship between social functioning deficits and relapse in these patients, identification of underlying factors is of significant importance. Thus, in this study, the contribution of each dimension of social cognition (Emotion Perception [EP], Theory of Mind [ToM] and Attributional Style [AS]) in predicting the social function of schizophrenic patients were examined.

Methods: The statistical population included all patients with chronic schizophrenia hospitalized in Shiraz chronic healthcare centers. Of them, a total of 62 patients with schizophrenia disorder were selected based on purposive sampling method from three chronic care centers and were evaluated using social cognition tools (Hinting Task, Face Emotion Identification Task, and The Ambiguous Intentions and Hostility Questionnaire) and the Social Functioning Scale (SFS).

Results: The results showed that ToM and EP predicted social functioning in people with schizophrenia but attributional style was not associated with social functioning.

Discussion: On the whole, ToM and EP are general abilities contributing in explaining social functioning. However, the importance of attributional bias is significant when evaluating the performance of a person in specific areas such as aggressive behaviors. 


\section{Highlights}

- Social cognition is a mental process that involves different abilities, including Theory of Mind (TOM), Emotion Perception (EP) and Attributional Styles (AS).

\section{Plain Language Summary}

Schizophrenia is one of the most severe psychiatric disorders that chronically affects different aspects of the patient's life. A large proportion of these people lose their jobs, abandon their education, break their marriage, destroy their friendship, isolate themselves, and experience repeated hospitalizations. Poor social functioning in these patients has made researchers to investigate the underlying factors associated with this disease. Social cognition is the infrastructure of normal social functions and includes a variety of dimensions including emotion perception, theory of mind and attributional bias. People with high social cognition in different aspects of social interaction experience more productive interactions and better social functioning. Understanding their emotions which are based on facial expressions, tone of voice (emotion perception), as well as ability to perceive the intentions of individuals (theory of mind) are the essential capabilities in social interactions. Some cognitive biases like attributing the cause of our failures to others (attributional bias) are other factors contributing to poor social functioning by facilitating communication damage such as pessimism, anger, and aggression.

Therefore, we decided to investigate the three dimensions of social cognition (emotion perception, mind theory, and attributional bias) in schizophrenia patients and their contribution to the social functioning. By identifying the related factors and attention to them in treatment and rehabilitation programs, we can offer more efficient services to improve the social functioning. The results indicate that emotion perception and theory of mind can predict the social functioning of these patients, while attributional bias cannot. Attributional bias appears to be more essential in explaining specific communication domains, such as aggressive behaviors, and it is not a good predictor of social functioning in general.

\section{Introduction}

chizophrenia patients experience major deficiencies in various areas of social functioning [1]. Deficiencies in social functioning plays an important role in predicting relapse and poor prognosis $[2$, $3]$, also it imposes huge costs on the patient and society. Therefore, these individuals' disabilities in different functional areas is very important. Thus, researchers have focused on identifying its underlying factors. Considering that the prerequisite of any social activity is the ability to rapidly process social stimuli, impaired social functioning in patients with schizophrenia can be related to their cognitive and processing deficits. Therefore, social cognition has recently been considered as one of the possible contributing factors in social functioning of individuals with schizophrenia [4-6].

Social cognition is a mental process that involves different abilities, including the inference of mental states of others (Theory of Mind [ToM]) [7], the recognition of emotional facial expressions (Emotion Perception [EP]) [8] and individuals' methods for explaining the causes of social incidents (Attributional Styles [AS]) [9]. Also, studies point to an impaired performance in social cognition dimensions in people with schizophrenia [10] These people not only demonstrate severely impaired performance in tasks of the ToM [11-13] and EP [14-16] but they also display a tendency to hostile and blaming attributes in explaining their life events $[17,18]$.

Neurological studies have also examined the social cognition deficits on the affected individuals and have emphasized on the role of amygdala in face perception [19]. They also suggested that the abnormalities of the amygdala activities in schizophrenia patients are associated with more problems in the identification of emotional facial expressions and judging others' emotional states [20]. Furthermore, given that the amygdala has a significant role in threat-processing, attributional bias (blaming others for negative events) in schizophrenia patients was attributed to excessive amygdala activity [21]. Moreover, consistent with studies demonstrating the fundamental role of activities in the medial prefrontal and orbitofrontal cortex in perceiving the mental state of others [2], studies on schizophrenia patients suggest decreased activity in their medial prefrontal cortex on the tasks of the TOM [22]. 
Several research studies have examined the association between the dimensions of social cognition in people with schizophrenia and their social functioning. The studies on the EP dimensions indicate that emotion perception is related to social behaviors and functioning [23]. Also, based on the theory of mind, the performance of schizophrenia patients in the theory of mind is not only related to social functioning [24, 25] and skills [4], but it also is able to predict social functioning in them $[25,26]$. Pinkham and colleagues (2015) also showed that ToM and EP were both able to predict social functioning in patients with schizophrenia [18]. However, studies on attributional bias and social functioning have reported contradictory findings.

One study found that attributional bias could predict some social behaviors such as aggression [27]. Another study indicated the relationship between attributional bias (blaming) and social functioning [17], while Pinkham et al. (2015) study reported no relationship between attributional bias (hostile and blaming) and social functioning [18]. Since social cognition as a multidimensional concept plays a significant role in explaining social functioning, it is necessary to design studies on concurrent analysis of different dimensions of social cognition. Identifying the role of each dimension in explaining the social functioning deficits in people with schizophrenia can discover the relationship between the variables and provide a basis for formulating rehabilitative interventions.

Social cognition is considered as a culturally-based mental process. Therefore, exploring the dynamics between the dimensions of social cognition and social functioning in different cultures deserves further attention. Accordingly, this research aimed to explore the contribution of three dimensions of EP, TOM and AS in predicting the social functioning of patients with chronic schizophrenia.

\section{Methods}

This was a correlational study in which ToM, EP and AS were the predictor variables and social functioning was the criterion variable. The statistical population of this study included chronic schizophrenia patients admitted to the Chronic Healthcare Centers in Shiraz, Iran with a history of frequent hospitalization. Of all, 65 schizophrenic patients were selected from the three healthcare centers of Aseman, Mahd-e Asadiyah and Al-Rahman. The samples were selected by the purposive sampling method and based on the diagnostic criteria of DSM-5 [28].
The inclusion criteria were lack of substance abuse and substance dependence and physical illnesses like epilepsy or head trauma. Most subjects' educational level was above primary-school, although two subjects were illiterate. The researcher read the questions of the tools of hinting task, Face Emotion Identification Task (FEIT), Ambiguous Intentions and Hostility Questionnaire (AIHQ), and SFS to the subjects and recorded their responses. This ensured that all subjects had the ability to understand the questions and to concentrate on their answers. Three subjects were excluded from the study due to their incomplete questionnaires and then finally the data of 62 subjects were analyzed.

\section{Research tools}

\section{The Hinting Task}

The Hinting Task was first developed by Corcoran et al. (1995) to evaluate the theory of mind. In this task, 10 short stories in the form of dialogues between two characters are presented to the subject. The characters drop a hint at the end of each story. The participants should make inferences about what characters meant. Scores vary between 0 and 20 with the greater scores demonstrating better understanding of other's intentions [29]. The reliability (Cronbach's alpha) of this task by Robert and the present study were measured as 0.65 and 0.67 , respectively [30].

\section{The Face Emotion Identification Task (FEIT)}

The Face Emotion Identification Task (FEIT) has been designed to identify facial emotions and consists of 19 facial expression photographs, that each shows one of the six basic facial emotions. The individual's performance is assessed by the total sum of correct answers with the higher scores indicating the participants' better understanding of facial expression [31]. The reported reliability of this task in the study of Ker and Nial (2001) and the present study were 0.77 and 0.74 , respectively.

\section{The Ambiguous Intentions and Hostility Ques-} tionnaire (AIHQ)

The Ambiguous Intentions and Hostility Questionnaire (AIHQ) is used for measuring attributional biases. Five hypothetical situations with ambiguous casualties are presented to the subjects and they are asked to imagine themselves in these situations. Also, they are asked about why these scenarios have happened (hostility bias). Then, the participants score the intention of the characters $(1=$ definitely not intentional to $5=$ definitely inten- 
tional), level of anger ( $1=$ definitely no to $6=$ definitely yes), and the level of blaming the guilty person ( $1=$ definitely no to $5=$ definitely yes) on a Likert-type scale. The blame index is obtained by summing up the mean score of all three questions. Ultimately, the participants are asked to state what they would do if the situations were real (aggressive bias).

Attributional bias includes three indexes of blaming, hostile attributional bias and aggressive attributional bias. Two independent evaluators score both hostility and aggression biases on a 5-point Likert-type scale [32]. In the study of Combs et al. [32] and the present study, the Intraclass Correlation Coefficient (ICC) were obtained as 0.86 . Moreover, the reported reliability (using Cronbach's alpha) for blame score in the study of Combs et al. and in this study were 0.92 and 0.94 , respectively.

\section{The Social Functioning Scale (SFS)}

The Social Functioning Scale (SFS) was developed to assess the social functioning in schizophrenia patients. It covers 7 areas including social conflict/isolation, interpersonal behaviors, independence-competence, in- dependence-performance, hobbies and interests, social behaviors, and employment. The total score of this scale is calculated by aggregating the mean scores of the seven subscales. The total score varies between 0 and 224 . The greater score reflects better social functioning. The reported reliability of this tool in Birchwood's and the current study were $0.80,0.81$, respectively [33].

Given that the study population consisted of patients with chronic schizophrenia admitted to the Chronic Healthcare Centers, there was no need to examine the employment criterion. However, their frequent returns to the family and community, along with their numerous social behaviors and interactions in the healthcare centers allowed evaluation of other aspects of social functioning in them.

\section{Results}

The subjects included 62 patients with schizophrenia disorder. All participants were male with a Mean \pm SD age of $42.73 \pm 9.71$ years and an average education of $9.01 \pm 2.70$ years. Table 1 presents more detailed informa-

Table 1. Mean \pm SD indices of research variable

\begin{tabular}{|ccc}
\hline Variables & Number & Mean \pm SD \\
\hline Hostile bias & 62 & $16.83 \pm 6.21$ \\
\hline Blaming score & 62 & $1.63 \pm 6.57$ \\
\hline Aggressive bias & 62 & $14.73 \pm 7.70$ \\
\hline Emotion perception & 62 & $6.51 \pm 3.53$ \\
\hline Theory of the mind & 62 & $10.73 \pm 4.86$ \\
\hline Social function & 62 & $89.47 \pm 27.87$ \\
\hline
\end{tabular}

IIranian Rehabilitation Journal

Table 2. Relationship between predictive variables and social function

\begin{tabular}{cccc}
\hline Variables & Social Function & Sig. & Number \\
\cline { 2 - 3 } & Correlation Soefficient & 0.5 & 62 \\
\hline Hostile bias & -0.07 & 0.5 & 62 \\
\hline Blaming score & -0.08 & 0.46 & 62 \\
\hline Aggressive bias & -0.09 & 0.001 & 62 \\
Theory of mind & 0.43 & 0.001 & 62 \\
\hline Emotion perception & 0.42 &
\end{tabular}


Table 3. Multiple regression analysis to predict social function

\begin{tabular}{|c|c|c|c|c|c|c|c|c|}
\hline Predictive variables & Beta & $\mathbf{t}$ & Sig. & $\mathbf{R}$ & $\mathbf{R}^{2}$ & f & df & Sig. \\
\hline Emotion perception & 0.29 & 2.13 & 0.03 & & & & & \\
\hline Theory of mind & 0.33 & 3.25 & 0.03 & & & & & \\
\hline Hostile bias & -0.12 & -0.78 & 0.51 & 0.528 & 0.279 & 3.82 & 5.61 & 0.005 \\
\hline Blaming & -0.07 & -1.02 & 0.72 & & & & & \\
\hline Aggressive bias & -0.16 & -0.1 & 0.16 & & & & & \\
\hline
\end{tabular}

IIranian Rehabilitation Journal

tion, in this regard. The correlation coefficient of ToM, EP and AS with social functioning are listed in Table 2.

The results suggest a significant correlation between the dimensions of the ToM $(r=0.43, \mathrm{P}=0.001)$ and $\mathrm{EP}$ $(\mathrm{r}=0.42, \mathrm{P}=0.001)$ with social functioning, but no significant relationship was found between the subscales of AS and social functioning. A multiple regression analysis (Enter method) was used in order to predict the variable of social functioning based on the indexes of the ToM, EP and attributional bias. The results revealed that the model used to predict the social functioning variable was significantly effective $\left(\mathrm{F}_{5,61}=3.82, \mathrm{P}<0.01\right)$. Based on the beta coefficient, variables of ToM and $\mathrm{EP}(0.33$ and 0.29 , respectively) were able to predict social functioning in schizophrenia patients. They can explain 0.279 of the changes in social functioning, as predictors (Table 3 ).

\section{Discussion}

In this study, the role of social cognition dimensions (EP, ToM and AS) in predicting social functioning was investigated. Consistent with the previous findings [4, 23-26], the results indicated a relationship between ToM, $\mathrm{EP}$ and social functioning in these individuals. These two dimensions were able to predict social functioning, but attributional bias (hostile bias, blaming and aggressive bias) was not associated with social functioning.

The results were consistent with the findings of Pinkham et al. [18], but they were in conflict with the findings of Waldheter et al. and Buck [17, 27]. The ability to process social stimuli is the prerequisite of social capability. Thus, the dimensions of social cognition like EP and ToM trigger various aspects of social functioning, including social interactions, independent life skills, and social behaviors [4]. This effect is through rapid processing of social stimuli $[4,34]$, and identification of social clues. Therefore, any defects in the dimensions of EP and
ToM as general abilities interrupt the rapid processing of social stimuli and identification of social clues $[4,5,7]$.

This interruption, in turn, disrupts the onset and maintenance of interactions, participation in social activities, and application of independent life skills. Attributional bias (hostile bias, blaming, aggressive bias), however, is probably associated with specific subscales of social behavior, like aggressive behavior [4]. In other words, the significance of attributional bias is best demonstrated when an individual's function is assessed within a specific domain like aggressive behavior, but when social function is evaluated generally, attributional bias would be of little importance [35].

Given that this research addressed social functioning in its general sense (based on the general scale of social functioning), the lack of relation between attributional bias and social functioning is understandable. In fact, social cognition dimensions, including the ToM and Ep make a major contribution to explaining the social function of schizophrenia patients. As a result, therapeutic interventions capable of amending social cognitive deficits in these patients can improve their social functioning as well [30].

It is suggested that future research on schizophrenia patients conduct interventions based on the Social Cognition and Interaction Training (SCIT), designed to improve the impaired dimensions of social cognition, i.e. ToM, EP and AS and consequently the process of improvement in the social function of these patients will be evaluated.

\section{Conclusion}

We identified the key determinants of social functioning in people with schizophrenia. The findings revealed that the components of ToM and EP make a major contribution in predicting social functioning. In this sense, 
these two variables facilitate the various aspects of social functioning in schizophrenia through the rapid processing of social stimuli and the identification of social clues. However, attributional bias only has a definitive role when certain aspects of social functioning, like aggressive behavior are evaluated. Considering the significant contribution of the ToM and EP to triggering social functioning, it is advisable to consider therapeutic interventions focused on the improvement of these dimensions.

One limitation of this research was that social cognition and social functioning variables were evaluated at a single time point, thus their causal relationship cannot be demonstrated. Therefore, it is suggested that future researchers conduct longitudinal studies to evaluate the relationship between social functioning and the dimensions of social cognition. Furthermore, given the importance of social cognition in explaining social functioning, it is recommended that all three dimensions of EP, ToM, and AS be considered in predicting aggressive behaviors in people with schizophrenia.

\section{Ethical Considerations}

\section{Compliance with ethical guidelines}

The purpose of the research was explained to the subjects by the researchers. The subjects' participation in this study was voluntarily and their responses were kept confidential. All subjects gave their informed consent. This research was confirmed by the Ethics Committee of the University of Social Welfare and Rehabilitation Sciences, Tehran, Iran under the ethical code of IR.USWR.REC.1395, 251.

\section{Funding}

This article was part of a $\mathrm{PhD}$ thesis of first author, conducted in the Department of Clinical Psychology, University of Social Welfare and Rehabilitation Sciences, Tehran, Iran. This research did not receive any specific grant from funding agencies in the public, commercial, or not-forprofit sectors.

\section{Conflicts of interest}

The authors certify that they have no affiliation with or involvement in any organization or entity with any financial, or non-financial interest in the subject matter or materials released in this manuscript.

\section{Acknowledgements}

We would like to appreciate the patients who cooperated in this research and the staff of the healthcare centers.

\section{References}

[1] Hooley JM. Social factors in schizophrenia. Current Directions in Psychological Science. 2010; 19(4):238-42. [DOI:10.1177/0963721410377597]

[2] Pinkham AE, Penn DL, Perkins DO, Lieberman J. Implications for the neural basis of social cognition for the study of schizophrenia. American Journal of Psychiatry. 2003; 160(5):815-24. [DOI:10.1176/appi.ajp.160.5.815] [PMID]

[3] Robertson BR, Prestia D, Twamley EW, Patterson TL Bowie CR, Harvey PD. Social competence versus negative symptoms as predictors of real world social functioning in schizophrenia. Schizophrenia Research. 2014; 160(1):136-41. [DOI:10.1016/j.schres.2014.10.037] [PMID] [PMCID]

[4] Couture SM, Penn DL, Roberts DL. The functional significance of social cognition in schizophrenia: A review. Schizophrenia Bulletin. 2006; 32(1):44-63. [DOI:10.1093/schbul/ sbl029] [PMID] [PMCID]

[5] Fett AKJ, Maat A, Investigators G. Social cognitive impairments and psychotic symptoms: What is the nature of their association? Schizophrenia Bulletin. 2011; 39(1):77-85. [DOI:10.1093/schbul/sbr058] [PMID] [PMCID]

[6] Mancuso F, Horan WP, Kern RS, Green MF. Social cognition in psychosis: Multidimensional structure, clinical correlates, and relationship with functional outcome. Schizophrenia Research. 2011; 125(2):143-51. [DOI:10.1016/j.schres.2010.11.007] [PMID] [PMCID]

[7] Kettle JW, O'Brien-Simpson L, Allen NB. Impaired theory of mind in first-episode schizophrenia: Comparison with community, university and depressed controls. Schizophrenia Research. 2008; 99(1):96-102. [DOI:10.1016/j.schres.2007.11.011] [PMID]

[8] Kee KS, Horan WP, Wynn JK, Mintz J, Green MF. An analysis of categorical perception of facial emotion in schizophrenia. Schizophrenia Research. 2006; 87(1):228-37. [DOI:10.1016/j. schres.2006.06.001] [PMID]

[9] Pinkham AE, Penn DL, Green MF, Buck B, Healey K, Harvey $\mathrm{PD}$. The social cognition psychometric evaluation study: Results of the expert survey and RAND panel. Schizophrenia Bulletin. 2013; 40(4):813-23. [DOI:10.1093/schbul/sbt081] [PMID] [PMCID]

[10] Green MF, Bearden CE, Cannon TD, Fiske AP, Hellemann GS, Horan WP, et al. Social cognition in schizophrenia, part 1: Performance across phase of illness. Schizophrenia Bulletin. 2011 38(4):854-64. [DOI:10.1093/schbul/sbq171] [PMID] [PMCID]

[11] Bora E, Yucel M, Pantelis C. Theory of mind impairment in schizophrenia: Meta-analysis. Schizophrenia Research. 2009; 109(1):1-9. [DOI:10.1016/j.schres.2008.12.020] [PMID]

[12] Savla GN, Vella L, Armstrong CC, Penn DL, Twamley EW. Deficits in domains of social cognition in schizophrenia: A metaanalysis of the empirical evidence. Schizophrenia Bulletin. 2012; 39(5):979-92. [DOI:10.1093/schbul/sbs080] [PMID] [PMCID]

[13] Sprong M, Schothorst P, Vos E, Hox J, Van Engeland H. Theory of mind in schizophrenia. The British Journal of Psychiatry. 2007; 191(1):5-13. [DOI:10.1192/bjp.bp.107.035899] [PMID]

[14] Fiszdon JM, Johannesen JK. Functional significance of preserved affect recognition in schizophrenia. Psychiatry Research. 2010; 176(2):120-5. [DOI:10.1016/j.psychres.2009.08.006] [PMID] [PMCID] 
[15] Tsui CF, Huang J, Lui SS, Au AC, Leung MM, Cheung $\mathrm{EF}$, et al. Facial emotion perception abnormality in patients with early schizophrenia. Schizophrenia Research. 2013; 147(2):230-5. [DOI:10.1016/j.schres.2013.04.019] [PMID]

[16] Leszczyńska A. Facial emotion perception and schizophrenia symptoms. Psychiatria Polska. 2015; 49(6):1159-68. [DOI:10.12740/PP/38919] [PMID]

[17] Buck B, Iwanski C, Healey KM, Green MF, Horan WP, Kern RS, et al. Improving measurement of attributional style in schizophrenia: A psychometric evaluation of the Ambiguous Intentions Hostility Questionnaire (AIHQ). Journal of Psychiatric Research. 2017; 89:48-54. [DOI:10.1016/j.jpsychires.2017.01.004] [PMID]

[18] Pinkham AE, Penn DL, Green MF, Harvey PD. Social cognition psychometric evaluation: Results of the initial psychometric study. Schizophrenia Bulletin. 2015; 42(2):494-504. [DOI:10.1093/schbul/sbv056] [PMID] [PMCID]

[19] Blackwood NJ, Howard RJ, Bentall RP, Murray RM. Cognitive neuropsychiatric models of persecutory delusions. American Journal of Psychiatry. 2001; 158(4):527-39. [DOI:10.1176/ appi.ajp.158.4.527] [PMID]

[20] Adolphs R, Tranel D, Hamann S, Young AW, Calder AJ Phelps EA, et al. Recognition of facial emotion in nine individuals with bilateral amygdala damage. Neuropsychologia. 1999; 37(10):1111-7. [DOI:10.1016/S0028-3932(99)00039-1]

[21] Combs DR, Penn DL. The role of subclinical paranoia on social perception and behavior. Schizophrenia Research. 2004; 69(1):93-104. [DOI:10.1016/S0920-9964(03)00051-3]

[22] Russell TA, Rubia K, Bullmore ET, Soni W, Suckling J, Brammer MJ, et al. Exploring the social brain in schizophrenia: Left prefrontal underactivation during mental state attribution. American Journal of Psychiatry. 2000; 157(12):2040-2. [DOI:10.1176/appi.ajp.157.12.2040] [PMID]

[23] Irani F, Seligman S, Kamath V, Kohler C, Gur RC. A metaanalysis of emotion perception and functional outcomes in schizophrenia. Schizophrenia Research. 2012; 137(1):203-11. [DOI:10.1016/j.schres.2012.01.023] [PMID] [PMCID]

[24] Zhu Y, Zhang L, Fan J, Han S. Neural basis of cultural influence on self-representation. Neuroimage. 2007; 34(3):1310-6. [DOI:10.1016/j.neuroimage.2006.08.047] [PMID]

[25] Piovan C, Gava L, Campeol M. Theory of Mind and social functioning in schizophrenia: Correlation with figurative language abnormalities, clinical symptoms and general intelligence. Rivista Di Psichiatria. 2016; 51(1):20-9. [PMID]

[26] Pijnenborg G, Withaar F, Evans J, Van den Bosch R, Timmerman $\mathrm{M}$, Brouwer $\mathrm{WH}$. The predictive value of measures of social cognition for community functioning in schizophrenia: Implications for neuropsychological assessment. Journal the International Neuropsychological Society. 2009; 15(2):23947. [DOI:10.1017/S1355617709090341] [PMID]

[27] Waldheter EJ, Jones NT, Johnson ER, Penn DL. Utility of social cognition and insight in the prediction of inpatient violence among individuals with a severe mental illness. The Journal of Nervous and Mental Disease. 2005; 193(9):609-18. [DOI:10.1097/01.nmd.0000177788.25357.de] [PMID]

[28] Association Psychology Association. Diagnostic and statistical manual of mental disorders (DSM-5®). New York: American Psychiatric Pub; 2013.
[29] Corcoran R, Mercer G, Frith CD. Schizophrenia, symptomatology and social inference: Investigating "theory of mind" in people with schizophrenia. Schizophrenia Research. 1995 17(1):5-13. [DOI:10.1016/0920-9964(95)00024-G]

[30] Roberts DL, Penn DL. Social Cognition and Interaction Training (SCIT) for outpatients with schizophrenia: A preliminary study. Psychiatry Research. 2009; 166(2):141-7. [DOI:10.1016/j.psychres.2008.02.007] [PMID]

[31] Kerr SL, Neale JM. Emotion perception in schizophrenia: Specific deficit or further evidence of generalized poor performance? Journal of Abnormal Psychology. 1993; 102(2):312-8 [DOI:10.1037/0021-843X.102.2.312] [PMID]

[32] Combs DR, Penn DL, Wicher M, Waldheter E. The Ambiguous Intentions Hostility Questionnaire (AIHQ): A new measure for evaluating hostile social-cognitive biases in paranoia. Cognitive Neuropsychiatry. 2007; 12(2):128-43. [DOI:10.1080/13546800600787854] [PMID]

[33] Birchwood M, Smith J, Cochrane R, Wetton S, Copestake S. The Social Functioning Scale. The development and validation of a new scale of social adjustment for use in family intervention programmes with schizophrenic patients. The British Journal of Psychiatry. 1990; 157(6):853-9. [DOI:10.1192/bjp.157.6.853] [PMID]

[34] Sterea R. The relationship between social cognition and functional outcomes in schizophrenia. Procedia-Social and Behavioral Sciences. 2015; 187:256-60. [DOI:10.1016/j.sbspro.2015.03.048]

[35] Harris ST, Oakley C, Picchioni MM. A systematic review of the association between attributional bias/interpersonal style, and violence in schizophrenia/psychosis. Aggression and Violent Behavior. 2014; 19(3):235-241. [DOI:10.1016/j.avb.2014.04.009] 
